\title{
Tuna-Dolphin II: a legal and economic analysis of the Appellate Body Report
}

\author{
MEREDITH A. CROWLEY* \\ Federal Reserve Bank of Chicago and University of Cambridge \\ ROBERT HOWSE* * \\ NYU Law School
}

\section{Summary of Tuna-Dolphin II and the Panel decision ${ }^{1}$}

In Tuna-Dolphin $I I,{ }^{2}$ Mexico challenged a US measure that monitored and enforced a private voluntary label on tuna, the 'dolphin-safe' label. While Mexico made some polemical claims that the US measure was 'coercive' and was not in the spirit of international cooperation with respect to dolphin conservation under the Agreement on the International Dolphin Conservation Program (AIDCP), ${ }^{3}$ a regional intergovernmental regime for dolphin protection, its more precise legal claims focused on two aspects of the US measure. First of all, as interpreted by the US Courts, the US legal framework required the prohibition of the use of the label on tuna marketed in the United States in any instance where the tuna was caught by a method involving encircling or setting upon dolphins. This method is attractive to tuna fishers in the Eastern Tropical Pacific (ETP), where Mexican boats fish for tuna, because in that region dolphins are known to swim with tuna. Mexico argued that by not allowing tuna fished in this way to be certified as dolphin-safe, even if no actual dolphin was killed despite the encircling or setting upon of dolphins, the United States violated 2.1 of the Agreement on Technical Barriers to Trade (TBT). Since this was a method typically used by Mexican fishers, not allowing it to qualify for 'dolphin-safe' labelling de facto limited the competitive opportunities for Mexican tuna in the United States.

Secondly, Mexico claimed that while the United States had a strict monitoring and enforcement scheme for tuna originating in the ETP, with respect to tuna fished

\footnotetext{
*Email: crowley.meredith@gmail.com.

**Email: howserob@gmail.com.

The opinions in this article are those of the authors and not necessarily those of the Federal Reserve Bank of Chicago or the Federal Reserve System.

1 This summary derives from Howse and Levy (2013).

2 Panel Report, United States - Measures Concerning the Importation, Marketing and Sale of Tuna and Tuna Products, Report of the Panel, WT/DS381/R, 15 September 2011.

$3 \mathrm{http} / / /$ ec.europa.eu/world/agreements/prepareCreateTreatiesWorkspace/treatiesGeneralData.do?step= 0\&redirect=true\&treatyId=627.
} 
outside the ETP, the United States allowed the label 'dolphin-safe' to be used based upon the self-declaration of the captain of the fishing vessel that no dolphins had been set upon and no dolphins killed. Mexico did produce some credible evidence that there was genuine harm to dolphins from tuna-fishing outside the ETP, thus putting into question the justification for treating tuna from the two geographic regions so differently. Since the United States made a distinction based upon geographical origin of the tuna, requiring much stricter regulatory enforcement within the ETP, the area where Mexican tuna was sourced, Mexico argued that there was a national-treatment violation. The Panel tended to conflate these rather different claims into a single claim of de facto discrimination with respect to the requirement of not setting on dolphins. While finding that Mexican 'tuna' and US 'tuna' were like products, the Panel rejected the conflated claim, based on the observation that at the time the measure was introduced, both US and Mexican fishing boats were using the method of setting upon dolphins, and thus the initial competitive effect on US and Mexican tuna of the banning of this method was the same. The choice of US fishers to avoid the method in order to be able to have their tuna certified as dolphin-safe and the Mexican fishers not to do so was a business decision, and did not reflect any lack of even-handedness in the requirement itself.

A threshold issue in the Tuna case was whether the US measure fell within the definition of a 'technical regulation' given that it was not a mandatory labelling scheme; there was no requirement that tuna be labelled for dolphin-safety (or unsafety). The measure merely ensured that when the claim 'dolphin-safe' was made, certain criteria were followed that provided an adequate assurance that dolphins were not being killed or hurt. Even though, to use the precise definitional terms of 'technical regulation' in TBT, the US measure did not make the characteristic in question - 'dolphin-safety'-mandatory for the product, which was defined as 'tuna' to be marketed in the United States, the Panel found that the measure was a technical regulation because it had some mandatory features.

Mexico also argued that there was a violation of TBT 2.2 because the US objective of informing consumers and protecting dolphins could be achieved if the United States were to permit both the label that it was now, in effect, imposing as the sole label and the alternative AIDCP dolphin-safe label, the latter allowing tuna to be caught in setting upon dolphins. According to Mexico, consumers could make an informed choice and if they wanted to ensure that tuna was not caught through setting upon dolphins, they could always choose the label certifying to that effect. The Panel held that, while having both labels freely available could create consumer confusion, it would be a less trade-restrictive alternative provided that this confusion was avoided through a requirement that the label on each can of tuna be accompanied by explanatory language that indicated the precise claims behind the particular label at issue. It is surprising that the Panel would find a violation of 2.2 based on the failure to adopt this information-intensive, least traderestrictive alternative of explanatory tuna labels, since it was never proposed by Mexico, and never discussed in the pleadings or the hearings. 
Finally, Mexico claimed that the United States was in violation of TBT 2.4 because it did not use the AIDCP alternative labelling scheme as a basis for its regulation. Mexico argued that the AIDCP was an international standard within the meaning of TBT 2.4. The Panel held that the AIDCP was an international standardization body, even though it is a regional organization to which only a small subset of WTO Members adhere, because at a particular point in time in the history of this organization there was a possibility for interested states outside the region to join it as parties to the treaty (this window had long passed). However, the Panel ultimately determined that there was no violation based on the finding that the standard was inappropriate and ineffective to achieve the US objective, since that objective concerned avoiding harms to dolphins explicitly connected to the technique of setting upon them, such as stress and trauma.

The Appellate Body (AB) upheld the Panel's finding that the US measure constituted a 'technical regulation'; reversed the Panel's finding of a violation of TBT 2.2 and significantly altered its analysis of 2.1 and 2.4, but ultimately found a violation of 2.1; given the rather sharp discrepancy of treatment in the US scheme between tuna fished in the ETP (the operating zone of Mexican tuna fishers) and outside the ETP, the AB held that there was a lack of evenhandedness, constituting a violation of 2.1 based upon the methodology it had set out in Cloves. ${ }^{4}$

\section{Legal analysis of Tuna-Dolphin /I $\mathrm{AB}^{5}$}

\subsection{The definition of a technical regulation}

The first paragraph of Annex I of the TBT Agreement defines a 'technical regulation' as a 'document that lays down product characteristics or their related processes and production methods, including the applicable administrative provisions, compliance with which is mandatory. It may also include or deal exclusively with terminology, symbols, packaging, marking or labelling requirements as they apply to a product, process or production method.' The TBT Agreement also applies to standards, which have a similar content to technical regulations, except that they are not mandatory.

Further, the TBT Agreement also applies to measures that assess the conformity of a product or its processing and production methods either with technical regulations or standards.

The US measure in this case did not require that tuna sold in the US were not caught by setting upon dolphins with purse sein nets. Nor did the measure stipulate that tuna be labelled 'dolphin-friendly' if it met the criteria in question or

\footnotetext{
4 Appellate Body Report, United States-Measures Affecting the Production and Sale of Clove Cigarettes, WT/DS406/AB/R, 4 April 2012.

5 Appellate Body Report, United States - Measures Concerning the Importation, Marketing and Sale of Tuna and Tuna Products, WT/DS381/AB/R, 16 May 2012.
} 
'dolphin-unfriendly' if it did not. Thus, the US measure was not obviously a description of a process and production method with which compliance is mandatory. Neither could the measure be understood as a 'labelling requirement', strictly speaking - in the ordinary meaning that the measure mandates that a product be labelled in a certain way. Nevertheless, the AB upheld the Panel majority in finding that the US measure was a 'technical regulation'.

There were a number of steps that led the $\mathrm{AB}$ to what we regard as this fundamentally erroneous finding. The first was that, relying on the Shorter Oxford English Dictionary, the AB chose a definition of requirement - 'a condition that must be complied with' - that allowed it to engage in the glissage that labelling requirements mean the conditions for the use of a label even if its use is itself voluntary, rather than that labelling is a condition on the importing, sale, marketing for sale etc. of the product (para. 186). Clearly, the OED definition is compatible with either meaning of 'condition'.

The $\mathrm{AB}$ should have gone further and considered 'condition' in the context of the TBT Agreement as a whole in one way or the other. Here, since TBT is a lex specialis to Article III:4 of the General Agreement on Tariffs and Trade (GATT), it is highly pertinent that Article III:4 contains the word 'requirements' and that at the time of the negotiation of the TBT Agreement there was an extensive jurisprudence on the meaning of the phrase 'laws, regulations and requirements' and that clearly the understanding was that this refers to measures that mandate the action in question, on pain of legal penalty or through some kind of government inducement. The US measure in Tuna-Dolphin II was clearly not a requirement in this sense since the use of a label was not mandated in the measure.

Understandably insecure about its interpretation of 'labelling requirements', the $\mathrm{AB}$ went on to admit that the US measure had some features of a 'standard' as well as of a 'technical regulation' in that it did not mandate the use of the 'dolphinfriendly' designation, but only that certain conditions be met in order that its voluntary use be permissible (para. 188).

What appeared to tip the balance for the $\mathrm{AB}$ was this. The US measure did not merely require that in order for a particular voluntary dolphin-friendly label to be used, certain conditions needed to be met. The US scheme went further and prohibited any alternative voluntary label or labelling scheme that made any representation concerning the tuna in question and the effects on dolphins of its production (para. 193). This is certainly a more nuanced approach to that of the Panel which seemed to suggest that governmental involvement in conformity assessment concerning a voluntary standard is a 'technical regulation' even where the only mandatory element is the stipulation that the product must not be represented as meeting the standard when it is not in conformity.

But the $\mathrm{AB}$ approach is still flawed. The requirement that tuna not be misrepresented as dolphin-safe, even by an alternative label, simply should not engage the same level of state responsibility under the TBT Agreement as where the government is giving producers no choice but to use a certain label. The level of 
justification of a 'technical regulation' required under TBT 2.2 makes the Member fully responsible for the overall labelling scheme, supposing that its preparation, adoption, and application is in the hands of the state. This is a very different matter than the state merely controlling the veracity of representations that private economic actors may or may not choose to make. We emphasize that this does not mean there is no state responsibility nor does it mean there is no mandatory element. It only means that the proper level of responsibility is that which pertains to conformity with a voluntary standard. Often courts in common law countries, or generally, under general consumer statues, will find legal liability for product claims the substance of which is completely unrelated to any governmental regulatory activity. It seems absurd to attribute to the state actions and omissions in the preparation or adoption or application of the standard or substantive norm on which a representation is based, just because legal liability attaches to misleading or deceiving consumers by the representation in question.

Again, we emphasize that state action to prevent consumer confusion or misinformation is subject to WTO norms, both under GATT and to some extent TBT. It is just that government mandating a certain substantive norm concerning a product or its production processes is very different from government limiting itself to preventing consumers from being misled or deceived. One may of course question whether the language by which the measure sought to prohibit claims of dolphin-friendliness, that did not meet the criteria for the dominant labelling scheme, was overbroad in light of its objectives, and that the government was not merely controlling misrepresentation but tipping the balance in favour of one substantive normative scheme over another. But these kinds of considerations could properly be dealt with in applying GATT Article III:4 and the disciplines of the TBT Agreement on conformity assessment.

Ultimately, one should perhaps not be too critical of the $\mathrm{AB}$, or at least be hopeful that it will distinguish Tuna-Dolphin II, in subsequent jurisprudence, on the basis that while voluntary there was considerable real world entanglement of the US authorities and private actors in the functioning of the particular labelling scheme in question. On these facts, it is not entirely unreasonable that the $A B$ would have held the US to a high level of state responsibility - one would like to think that would be the case where government is controlling the veracity or clarity of private sector representations, but completely at arm's length from any particular voluntary labelling scheme that private actors have adopted.

\subsection{Product-related production and process methods (PPMs)}

It has often been assumed that the expression in Annex I, para. I, 'product characteristics or their related processes and production methods' indicates that the technical regulations do not include PPMs that leave the physical characteristics of the product unaffected. There was in fact no textual-or contextualreason to assume that 'characteristics' means only physical characteristics. In the case of Tuna-Dolphin II, the characteristic at issue, dolphin friendliness, is not a 
physical characteristic. Notably, in determining whether the US measure was a technical regulation, the $\mathrm{AB}$ never even considered the notion that 'characteristic' might mean physical characteristic. And indeed there was no reason for the AB to consider notions invented by academic and other commentators, however widespread the canard.

Since the $A B$ gave no thought to the idea of imposing on the expression 'characteristic' a restrictive meaning completely unsupported by the text, it did not have to consider the significance of the difference between the first and second sentence of the definitional paragraph of Annex 1 in regard to PPMs. The second sentence applies to packaging and 'labelling requirements' and refers to PPMs without the qualifier in paragraph 1 that they relate to the characteristics of the product. Had the AB found for example that 'characteristics' in the first sentence of 2.1 meant physical characteristics, it would then have had to address whether, unlike the case for other technical regulations, PPMs in respect to labelling requirements need not be related to the physical characteristics of products. Without such a finding, the $\mathrm{AB}$ would have been compelled to the conclusion that the entire US measure falls outside the definition of a technical regulation. Had the AB restricted 'characteristics' in the first sentence to physical characteristics and yet found (as hypothesized) that in the case of a labelling requirement a PPM need not be related to product characteristics, it would then have had to restrict its consideration under TBT to the aspect of the measure that fell within its definition of labelling requirement, namely conditions to be met to conform to the description in the particular label, 'dolphin-friendly'. Yet recall that the aspect of government involvement that convinced the $\mathrm{AB}$ that the measure was a technical regulation was the prohibition on any alternative representation or claim concerning the impact on dolphins of the tuna in question. This purportedly broad prohibition is different from a labelling requirement as the $\mathrm{AB}$ sees it. And indeed elsewhere in its report the $\mathrm{AB}$ refers to the description of a technical regulation in the first sentence in the defining para of Annex 1, confirming that it is addressing aspects of the US measure beyond those denoted by the description in the second sentence.

By accepting that 'characteristics' in the first sentence is not confined to physical characteristics, the $\mathrm{AB}$ has thus left unresolved two puzzles. What does in fact product-related mean in the first sentence, and why does it not qualify the reference to PPMs in the second sentence?

To the first question, there is a rather straightforward answer. TBT is an agreement that concerns traded goods and their competitive opportunities. PPMs that do not relate to a specific traded good cannot be the focus of a complaint under TBT. Thus, where a PPM measure concerns trade in services (for example, norms regarding how engineers and architects design a nuclear power plant that affect competitive opportunities of such service providers from other WTO members), TBT does not apply; the complaint is not concerning competitive opportunities for traded goods. Similarly a complaint concerning a WTO Member's exclusion from patenting of a certain process, where it does not concern competitive opportunities 
for the resulting product in the regulating Member's market would normally be addressed under TRIPs not TBT.

There is however a class of PPMs that do not relate to the characteristics of a specific product strictly speaking but do relate to its competitive opportunities in the market of the regulating Member.

Take for example a requirement that the production of the packaging of a good does not result in certain levels of toxic waste. The package is separable from any characteristic of the good, physical or otherwise, but specifying its manner of production can affect the marketing, sale etc. of the product in the regulating Member's territory. A similar case is a requirement that a particular methodology or instrument be used to calculate the volume or weight of a product for purposes of labelling. We can see here clearly why different language concerning PPMs is needed in the second sentence as opposed to the first. But the intent not to apply TBT where a PPM is unconnected to a traded product including the conditions of its marketing and sale seems fairly clear.

Some have suggested the rather non-sensical reading that by virtue of sentence one, only PPMs related to physical characteristics are disciplined by TBT, whereas in the case of labelling, etc. under the second sentence, all PPMs are disciplined. This would lead to the absurd, or at least highly counterintuitive, result that a highly trade-restrictive measure such as a ban based on a non-product related PPM would not be left entirely undisciplined as a technical regulation, whereas less trade-restrictive labelling requirements would.

\subsection{National Treatment/MFN (TBT 2.2)}

The like products analysis of the Panel was not appealed by the United States and therefore the $\mathrm{AB}$ did not address it. The Panel had found that the relevant universe of like products was 'tuna' or products containing tuna. Given the comments by the Appellate Body in US-Clove Cigarettes ${ }^{6}$ about the importance of defining correctly the product universe in light of the precise claim of discrimination by the complainant, one may well question whether the Panel came to a correct finding here. The competitive relationship being asserted by Mexico was between Mexican tuna caught in purse seine nets but otherwise qualifying as dolphin-friendly under the US labelling scheme and US or other tuna not caught in purse seine nets. Mexico was $n o t$ arguing that from the perspective of competition all tuna is the same, whether dolphin-friendly or not. This would indeed have been to the detriment of its case, which was premised on the notion that, because consumers do distinguish dolphinfriendly and unfriendly-tuna and do not treat them as like products, access to the dolphin-friendly designation provides important competitive opportunities.

6 Appellate Body Report, United States-Measures Affecting the Production and Sale of Clove Cigarettes, WT/DS406/AB/R, 4 April 2012. 
Following the approach it set out in US-Clove Cigarettes, the $\mathrm{AB}$ considered that the determination of whether there was treatment less favourable of imported Mexican tuna should begin with the consideration of whether the US measure altered the conditions of competition between domestic US and imported Mexican tuna to the detriment of the imports. If such a detrimental impact were found, then it would still be open to the defendant to show that the impact was exclusively due to a legitimate regulatory distinction and thus did not amount to discrimination within the meaning of Article 2.1, interpreted in light of object and purpose of TBT as disclosed in the Preamble to the agreement.

The Panel below had found that the requirement that dolphins not be set upon with purse seine nets was national origin-neutral and did not result in the alteration of the conditions of competition between domestic US and imported Mexican tuna because Mexican operators could have the same access to the US market as domestic operators simply through complying with the national-origin-neutral condition of not setting upon dolphins with purse seine nets.

The $\mathrm{AB}$ rightly criticized this analysis as too simplistic (para. 225). The mere fact that a condition is, on its face, national origin-neutral is no guarantee that it actually operates in an origin-neutral manner. For example, a facially origin-neutral requirement may in fact be determined in such a manner as to establish conditions of competition that favour domestic operators and deny competitive opportunities to imports. As the $\mathrm{AB}$ noted, the approach of the Panel would amount to reversing the long-standing jurisprudence that national treatment disciplines extend to $d e$ facto discrimination. At the same time, the $\mathrm{AB}$ did not say that every differential impact that results from the operation of an origin-neutral measure constitutes in itself a detrimental impact pointing to a finding of treatment less favourable. Rather each such impact must be assessed as potentially relevant to whether there is treatment less favourable. Thus, in the Dominican-Republic Cigarettes ${ }^{7}$ case, the $\mathrm{AB}$ considered a lump-sum bond or deposit requirement on cigarettes that the complainant argued imposed a higher per unit cost on foreign cigarette operators. The $\mathrm{AB}$ found that this requirement did not alter the conditions of competition to the detriment of imports because the higher per unit cost was simply a function of the fact that there were lower sales of foreign cigarettes as opposed to domestic cigarettes. Assuming that this situation was due only to current market conditions and not to any actions of the defending state, the $\mathrm{AB}$ found that even though there was a disparate impact this impact did not amount to de facto discrimination. In Tuna-Dolphin II, the AB expresses this through the notion of evenhandedness. A scheme may lack evenhandedness in its design and structure even if it does not contain any explicit, facial distinctions based on the national origin of products, such that as a formal matter both domestic and imported products have access to

7 Appellate Body Report, Dominican Republic-Measures Affecting the Importation and Internal Sale of Cigarettes, WT/DS302/AB/R, 25 April 2005. 
the same competitive opportunities. An example of a measure that did not impose explicit national origin-based conditions but nevertheless lacked evenhandedness is to be found in one of the earliest GATT cases addressing de facto discrimination, the Canada-Beer ${ }^{8}$ case. Certain Canadian provinces set a minimum price requirement for beer - both domestic and imported US beer sold at or above that minimum price were equally eligible to be sold in the markets in question. However, the minimum price itself was determined according to a benchmark that used computations based on the costs of domestic brewers, which were relatively higher than costs of competing US brewers. This had the effect of denying to the US brewers the ability to exploit their distinctive advantage of low cost structures in competing in the Canadian provincial markets. This is a perfect illustration of how a measure can on its face be origin-neutral but have elements of nonevenhandedness buried or entrenched in its structure and operation.

The $\mathrm{AB}$ having (in our view correctly) reversed the Panel for curtly assuming that, where detrimental impact does not derive from facially origin-based distinctions, there cannot be discrimination in the relevant sense, the question is whether the $A B$ itself moved too quickly to the conclusion that the purse seine net requirement pointed to the kind of non-evenhandedness that would amount to de facto discrimination (para. 235). In what way was the requirement not to use the purse seine method inherently tilted in favour of domestic tuna to the disadvantage of Mexican imports? Is there some intrinsic obstacle to Mexican fishers abandoning the use of purse seine nets that explains why they are still used? The mere fact that Mexican fishers have not abandoned purse seine nets while US fishers have does not seem sufficient. Thus, the AB itself notes in its report that the Panel found as a fact that both US and Mexican fishers set upon dolphins with purse seine nets at the time the US measure was introduced; US fishers changed their practices but Mexican fishers chose not to (paras. 206-207). While the Panel's legal analysis may have been faulty, in appearing to suggest that only facially national-origin related differential treatment is relevant, the Panel made the important factual finding that 'any particular adverse impact felt by Mexican tuna products on the US market' was 'primarily the result of factors or circumstances unrelated to the foreign origin of the product' (emphasis added: para. 7.378). Given that the AB did not conclude that this factual determination was tainted by any violation of DSU 11 , it is completely obscure why the $\mathrm{AB}$ came to a preliminary conclusion of de facto discrimination in this case. If one accepts the factual finding of the Panel then the result would logically have to be the same as in Dominican Republic-Cigarettes. Indeed, one reason that the Panel may have not explicitly addressed de facto discrimination is that it found no facts that pointed to hidden, indirect, or structural

8 GATT Secretariat, Panel on Import, Distribution, and Sale of Alcoholic Drinks by Canadian Provincial Marketing Agencies', Report of the Panel adopted on 22 March1988, L/6304-35S/37, 5 February 1988. 
discrimination. But the sentence just cited from the Panel report indicates that the Panel certainly at least turned its mind to whether such facts existed. In sum, the AB inferred a 'detrimental impact' from the mere fact that Mexican and US fishers currently have different practices concerning setting on dolphins with purse seine nets, contrary to the AB's own methodology, set out in this report as well as in Dominican Republic-Cigarettes, the AB failed to consider if, or explain why, the differential impact resulted from lack of evenhandedness in the US measure. It is probably impossible to design a regulation that is completely neutral in its competitive effects on diverse economic actors, domestic and foreign. This cannot be the meaning of 'evenhandedness'. Rather, it is important to look, as the AB did in cases as old as Chile-Alcohol ${ }^{9}$ and as recent as Dominican Republic-Cigarettes, at whether the differential impact results from features of the design and structure of the scheme that are tilted or skewed somehow in favour of domestic production. This might be the case, for example, if a fishing technique were required that was, due to climatic or geographical conditions, inherently un-viable in the waters where the Mexican industry had organized itself to fish. But there were no findings of fact in the Panel report that pointed to any such situation.

In any case, having found a detrimental impact, the $A B$ went on to consider whether that impact was exclusively attributable to a legitimate regulatory distinction. The $\mathrm{AB}$ defined the detrimental impact in this section of its report rather differently than what we have just seen in the immediately prior section: 'The aspect of the measure that causes the detrimental impact on Mexican tuna products is ... the difference in labelling conditions for tuna products containing tuna caught by setting on dolphins in the ETP, on the one hand, and for tuna products containing tuna caught by other fishing methods outside the ETP, on the other hand' (para. 284). At this point, the AB seems to actually be proposing a theory of non-evenhandedness that, as we have noted, seemed lacking in the immediately prior analysis, namely that the detrimental impact is not simply due to the no-purse seine requirement in and of itself but rather the operation of the scheme so as to allow access to the label for competing producers who put dolphins at risk through other fishing techniques in other waters where the Mexican industry does not operate. In other words, the non-evenhandedness comes from the design and structure of the scheme, which focuses on threats to dolphins in the ETP through techniques used by the Mexican fishers and ignoring threats from other fishing practices in other waters.

While the US scheme established that setting on dolphins with purse seine nets was incompatible with the dolphin-safe label, whether in the ETP or elsewhere, outside the ETP it was possible for the captain of the boat to self-certify that this

9 Appellate Body Report, Chile-Taxes on Alcoholic Beverages, WT/DS87/AB/R, WT/DS110/AB/R, 13 December 1999. 
practice was not being used, whereas in the ETP the certification of an independent observer on the boat was required. Moreover, outside the ETP access to the dolphin-safe designation was possible without any certification that dolphins had not been killed in the process of fishing the tuna in question.

The US sought to justify these disparities by the fact that association of tuna and dolphins is rare outside the ETP, and evidence of dolphin mortality not strong enough to justify the costs of requiring certification as a precondition to use of the dolphin-safe designation. Mexico presented some studies that indicated some evidence of tuna fishing-associated, or at least fishing-associated dolphin mortality outside the ETP. The validity and significance of this evidence was strongly contested in the Panel proceedings.

Ultimately, the AB concluded that the full discrepancy between the treatment of ETP and non-ETP tuna could not be exclusively attributed to a legitimate regulatory distinction. The $\mathrm{AB}$ partly accepted and partly rejected the US cost-benefit argument. It accepted that the much greater threat to dolphins in the ETP could justify the requirement of independent observers in the ETP (footnote 612 and accompanying text) while relying on self-certification (captain's certification) outside the ETP with respect to the non-purse seine net requirement. But the AB rejected the cost-benefit argument with respect to the absence of any certification concerning non-dolphin-mortality from other fishing methods outside the ETP. This rejection was based entirely on the observation that (just as with the non-purse seine net rule outside the ETP) it would be possible to use captain's certification with respect to dolphin non-mortality from other fishing methods (para. 296). Thus, requiring certification concerning dolphin non-morality outside the ETP did not entail requiring independent observers on each boat. In this sense, the AB was able to accept the US argument that greater rigor in certification was justified in the case of the ETP given the significantly greater threats to dolphins, while rejecting the notion that paying no attention whatever to dolphin-mortality from other fishing techniques outside the ETP was fully justified by the legitimate US concerns of dolphin protection and consumer information, given the different level of risks in the ETP and outside the ETP.

It is not surprising therefore that the US has implemented the $\mathrm{AB}$ decision by requiring non-ETP captain's certification of dolphin non-mortality from fishing methods other than setting on dolphins. This pinpoints the precise concern that led the $\mathrm{AB}$ to find a violation of 2.1. It does not reduce in any way the effectiveness of the scheme in relation to the ETP - rightly the main concern of both consumers and the US government - and it might result in some additional dolphin lives being saved, at relatively modest cost. At the same time, jurisprudentially, the AB needs to articulate with greater clarity the steps by which de facto discrimination is established under the National Treatment obligation, whether in GATT or TBT. One can agree with the $\mathrm{AB}$ that all evidence of disparate impact of a measure on competing foreign producers is relevant to assessment of whether de facto discrimination exists, but the question is how this evidence is to be weighed and 
evaluated in relation to the structure and design of the measure in order to come to an overall conclusion as to whether in the AB's words there is a lack of 'evenhandedness'. We have pointed out the apparent inconsistencies in the AB's own articulation of 'detrimental impact' in this report, as well as tensions with the way in which the evidence was weighed and evaluated in Dominican RepublicCigarettes.

A final note. After US-Clove Cigarettes, there was much discussion and speculation on whether the $\mathrm{AB}$ approach of considering whether detrimental impact is attributable exclusively to a legitimate regulatory distinction would apply equally or at least mutatis mutandis to Article III:4 of the GATT. In Tuna-Dolphin $I I$, the $\mathrm{AB}$ appears to take an integrated approach to the analysis of discrimination under TBT and GATT, in no way indicating that the analytics it is using are specific to TBT. Thus the $\mathrm{AB}$ applies without qualification or distinction that jurisprudential acquis on National Treatment in the GATT to the analysis under 2.1. There is no reason why a responding Member could not argue under Article III of the GATT that, despite features of the design and structure of its measure appearing to be non-evenhanded in their impact on competing imported products, these features can in fact be fully explained by a legitimate regulatory distinction. Indeed, applying the second sentence of Article III:2 in Chile-Alcohol (which reflects the overall object and purpose of National Treatment, expressed in both III: 1 of GATT and the Preamble of TBT), the AB justified its finding of de facto discrimination in that case by Chile's ultimate failure precisely to explain the design features of its scheme in terms of distinctions arising from legitimate regulatory objectives.

\section{4 'Unnecessary Obstacle to Trade' (TBT 2.2)}

Article 2.2 reads:

Members shall ensure that technical regulations are not prepared, adopted or applied with a view to or with the effect of creating unnecessary obstacles to international trade. For this purpose, technical regulations shall not be more trade restrictive than necessary to fulfill a legitimate objective, taking account of the risks non-fulfillment would create. Such legitimate objects are, inter alia: national security requirements; the prevention of deceptive practices; protection of human health or safety; animal or plant life or health, or the environment. In assessing such risks, relevant elements of consideration are, inter alia: available scientific and technical information, related processing technology or intended end-uses of products.

The various qualifications on the substantive criterion of necessity - for example ('taking account of the risks non-fulfilment would create') least trade restrictive distinguish the TBT Agreement from Article XX of the GATT. Article XX provides a means of justifying measures that have already been found to violate some provision of the GATT. In the case of TBT 2.2, unlike GATT Art. XX, it is not a matter of 'saving' measures that have already been impugned, the burden of proof 
is logically on the complainant to show that a less trade-restrictive alternative does exist, which would fulfil the defending Member's legitimate objective.

Under TBT 2.2, the obligation to ensure the least trade restrictiveness of regulations is relative to the kinds of risks that would arise in the absence of the regulations. Deliberation about the choice of regulatory instrument can be a costly and time-consuming process. How far a Member should be expected to go in exhausting all the regulatory alternatives to find the least trade-restrictive alternative is logically related to the kind of risk it is dealing with. Where what is at stake is a well-established risk to human life itself, a Member may be expected to act rapidly, rely on the scientific acquis to a large extent, and tend towards the more obviously effective and enforceable kinds of regulatory tools, as opposed to the more sophisticated and speculative ones.

Article 2.2 explicitly lists among the relevant elements of consideration in assessing risk 'available scientific and technical information'. This suggests that a WTO Member is not required to adopt or even explore a less trade-restrictive alternative that has not been shown as effective in achieving its legitimate objective on the basis of existing scientific and other relevant information.

Generally speaking, the parties and the Panel approached the application of TBT 2.2 based on the existing jurisprudence of GATT Article XX. Thus, the analysis revolved around the question of whether there was a reasonably available less trade-restrictive alternative measure that could make an equivalent contribution to the US chosen level of protection. The Panel found that the extent to which the US measure fulfilled the objectives of dolphin protection and consumer information was limited in that the measure provided little real assurance to consumers that tuna caught outside the ETP was in fact dolphin-safe (this concerns features of the US measure we discussed above in connection with the analysis of TBT 2.1). Since the assurances of dolphin-safety under the US measure were incomplete or imperfect, the Panel reasoned, an alternative measure could also involve incomplete or imperfect assurances of dolphin-safety while still making an equivalent contribution to the US chosen level of protection.

On this basis the Panel considered Mexico's argument that 'A less trade restrictive way of fulfilling the objectives would be to create dolphin-safe standards rather than a technical regulation' (Mexico, 2nd Written Submission, para. 210, emphasis added). (In other words, the US objectives can be fulfilled by the operation of voluntary standards by the various labelling and certification schemes, with no requirement of government action through technical regulations.) The basis for Mexico's argument was its assertion in its first written submission to the Panel that the operation of the AIDCP was making a sufficient contribution to the US objectives that no further intervention by the US government was necessary: 'in the absence of the US measures, the preservation of dolphin stocks in the ETP fishery will continue to be accomplished by the requirements and procedures of AIDCP' (Mexico, First Written Submission, para. 244, emphasis added). 
Mexico's argument would only be plausible if the US level of protection could be inferred from the features of its scheme that disclose limited concern for the achievement of dolphin-safety (namely, the relative lack of enforcement of dolphin-safety standards outside the ETP). In some sense, Mexico's argument entails not so much the proposal of an alternative measure but the assertion that the US measure makes no contribution at all to the achievement of its chosen level of protection (using the non-ETP baseline) since that level of protection (within the ETP) is already being achieved through the AIDCP.

The Panel however, did not base its finding of a violation on the comparison of the US measure with the alternative proposed by Mexico (no US technical regulation but continued operation of the AIDCP regime) but rather on a comparison with a very different alternative that the Panel itself constructed. The Panel's concern with Mexico's proposal of no US government involvement is that it could result in two voluntary labels, the US one and the AIDCP one, operating side by side in the marketplace, with the result of consumer confusion, and thus non-fulfilment of the US consumer information objective. Thus, the Panel made up something different. In paragraph 7.575 of its Report, the Panel described and found an alternative regulatory scheme, less restrictive of trade and capable of fulfilling the US legitimate objectives, with the following features: the United States would continue to ensure compliance with the 'dolphin-safe' designation but instead would permit two separate labelling and certification schemes, each of which defined 'dolphin-safe' in a somewhat different manner. The labels in each case would be required to disclose to consumers the relevant meaning of 'dolphinsafe' that corresponded to the particular tuna in question.

The $\mathrm{AB}$ confirmed that the analysis of whether the measure conforms to the requirements of 2.2 normally entails a consideration of whether there is a 'possible alternative measure that is less trade restrictive, makes an equivalent contribution to the relevant objective, and is reasonably available' (para. 323). The AB also, noted, however, its jurisprudence in respect to Article XX of the GATT (Korea-Beef), ${ }^{10}$ that suggested that in some instances a measure might be 'necessary' even though it is not 'indispensable' (footnote 642). If what the $A B$ is suggesting in this footnote is that the same logic applies to the meaning(s) of necessity in TBT 2.2, then even if an alternative measure is identified that is found to be 'less trade restrictive, makes an equivalent contribution to the relevant objective and is reasonably available' and thus the measure under scrutiny is not 'indispensable' it would still be open to the responding Member to argue that while not 'indispensable' it has a sufficiently close and proportionate relationship to the objective as to be 'necessary'. Finally, the $\mathrm{AB}$ identified at least two

10 Appellate Body Report, Korea-Measures Affecting Imports of Fresh, Chilled and Frozen Beef, WT/ DS161/AB/R, WT/DS169/AB/R, adopted 10 January 2001. 
circumstances where there would be no need to proceed by way of a comparison with possible alternative measures: first where the measure made no contribution to the objective (which as noted, seemed to be Mexico's actual argument in its written submissions to the Panel in this case) or second where the measure is not trade restrictive (footnote 647).

According to the $\mathrm{AB}$, the normal way of proceeding under 2.2 would be for the complainant to identify possible alternative measure(s), making a prima facie case that the alternative measure (or measures) is less trade restrictive, reasonably available, and makes an equivalent contribution, and then, in turn, for the responding Member to attempt to rebut this by showing that in fact the alternative measure does not have one or more of these features.

This brings us to the AB's reversal of the Panel's finding of a violation of TBT 2.2. As noted, the Panel's finding of a violation was based on a possible alternative measure that the Panel itself constructed, not the one identified by Mexico (that the Panel found could lead to consumer confusion and non-fulfilment of the US consumer information objective). Confusingly, and arguably erroneously, the AB directed itself to the Panel's comparison of the alternative measure proposed by Mexico (para. 330), not the comparison that actually led to the Panel's finding of a violation. The fundamental flaw that the $\mathrm{AB}$ saw in the comparison in question was that the Panel focused on the overall contribution of the US measure and the alternative measure, taking conditions in the ETP and non-ETP together (and thus, as noted above, that the US measure and the alternative measure each addressed imperfectly or incompletely the concerns in question). Instead, since the AIDCP scheme does not apply outside the ETP, the AB said that the proper comparison was between the respective contributions of the two schemes to the US objectives with respect to the situation within the ETP. Thus, the apparently lower level of protection or lesser achievement of its objectives acceptable to the US inferred from its treatment of non-ETP tuna would be irrelevant to any proper comparison. The appropriate way for the $\mathrm{AB}$ to have proceeded would have been to make clear it was reversing the Panel finding of a violation of 2.2 based solely upon its failure to restrict its comparison to the ETP, and then having so reversed, that it was completing the analysis. This would have provided a clear jurisprudential basis for considering the alternative measure proposed by Mexico, not the one constructed by the Panel on which it found a violation of 2.2.

Comparing the contribution of the US measure and the alternative proposed by Mexico to US objectives within the ETP, the AB held as follows:

We note, in this regard, the Panel's finding, undisputed by the participants, that dolphins suffer adverse impact beyond observed mortalities from setting on dolphins, even under the restrictions contained in the AIDCP rules. Since under the proposed alternative measure tuna caught in the ETP by setting on dolphins would be eligible for the 'dolphin-safe' label, it would appear, therefore, that the alternative measure proposed by Mexico would contribute to both the consumer information objective and the dolphin protection objective to a lesser degree than 
the measure at issue, because, overall, it would allow more tuna harvested in conditions that adversely affect dolphins to be labelled 'dolphin-safe'. ${ }^{11}$

Having incorrectly substituted the comparison suggested by Mexico for the comparison on the basis of which the Panel actually found a violation of 2.2, the $\mathrm{AB}$ seemed even to misconstrue Mexico's proposed comparison. As the passage cited in the previous paragraph indicates, the $A B$ appears to have understood Mexico's suggested alternative as that the US would, under its scheme, make the 'dolphin-safe' label available to all tuna caught in accordance with the AIDCP rules. But this is not what Mexico was proposing either in its first or second submission. Instead, Mexico's alternative was that the US withdraw from establishing and enforcing the criteria for 'dolphin-safety' altogether. This would leave the US label as a US industry-supervised standard, while at the same time allowing the designation 'dolphin-safe' for tuna fished in accordance with the alternative AIDCP scheme. In our view, had the $A B$ understood correctly the Mexican proposed alternative, it would have been required to do a more complex analysis to determine whether this alternative made an equivalent contribution to the US objectives.

The beginning point of such an analysis would necessarily be a prediction of how the alternative measure would affect consumer behaviour. The co-existence of two schemes, neither of which is monitored and enforced by the US government, might have a number of possible effects on consumers. Consumers concerned with dolphin-safety might be confused by the existence of two different labels with the same designation 'dolphin-safe' and possibly different meanings to the claim of dolphin-safety, and they might respond by switching from tuna to substitute products (the empirical evidence is that this is precisely what US consumers did when problems of dolphin mortality first arose and until their confidence was won in the US 'dolphin-safe' label) (Teisl et al., 2002). If this were to occur, then the US dolphin protection goals would be fulfilled perhaps to an even greater extent than with the existing measure. However, the consumer information goal would be undermined, as consumers would not feel confident that they had the information they required to exercise their preference to eat dolphin-safe tuna and thus would choose between two alternatives each less attractive, eating tuna that might well not be dolphin-safe, or giving up on tuna. Some consumers, even if not confused, might have insufficient confidence in labels not backed by US government monitoring and enforcement, such that they also would switch out of tuna.

Such possible effects are relevant to whether the alternative measure would be less trade restrictive. A measure that has the effect of reducing sales of tuna both domestic and imported seems more not less restrictive of trade in tuna.

11 World Trade Organization, United States - Measures Concerning The Importation, Marketing And Sale Of Tuna And Tuna Products AB-2012-2, WT/DS381/AB/R, 16 May 2012, p. 127. 
An alternative, more optimistic view is that the co-existence of two non-governmentally verified labelling schemes would provide more refined or better information to consumers, allowing them to make choices that more exactly reflect their preferences. Thus, it might be argued that there are some consumers in the US market who are concerned by dolphin mortality but not by the specific additive risks to dolphins from setting upon them with purse seine nets; these consumers would prefer tuna caught in accordance with the AIDCP rules if it cost less than tuna bearing the US 'dolphin-safe' label (which does address the additional harm from setting on dolphins with purse seine nets). The co-existence of the two labels enables an optimal welfare outcome for this particular group of consumers while still allowing an optimal outcome for those consumers who do care about the additional harmful impact from purse seine fishing, and would prefer to pay more for a credible assurance that the tuna they are eating is not fished in that way. Thus, and this seems to have been the logic of Mexico's argument, the alternative does better than the US measure in achieving the goal of consumer information or consumer protection. On the other hand, if we consider the US dolphin protection goals, to the extent that the alternative empowers a group of consumers who are okay with dolphins being set upon with purse seine nets (or more precisely are unwilling to pay more to avoid this), it will result in higher demand for tuna caught using the purse seine technique, and therefore, at the margin, more harm to dolphins. Thus, even if it makes an equivalent or greater contribution to the consumer information objective of the United States, the measure does not make an equivalent contribution to the achievement of the US dolphin-protection objective in the ETP. A Member is entitled to achieve all of the legitimate objectives: this is fundamental to the 'right to regulate' under the TBT Agreement. In its measures, a Member is free to accept a lesser degree of fulfilment of one objective in order to achieve a greater degree of fulfilment of the other (where there is a trade-off between them). However, a Member cannot be required to accept a trade-off between the fulfilment of two different objectives that the Member itself has not chosen. Thus even if an alternative measure gave consumers more informed choices, if at the same time it led to a lesser degree of achievement of the dolphin protection objective, the US would not be violating 2.2 by failing to adopt the alternative. To hold otherwise would, in effect, deny the sovereign right of a Member to determine its level of protection in respect of each objective.

Had the AB properly considered the comparison between Mexico's proposed alternative and the US measure, it would have come to the same conclusion that the US has not violated 2.2, since, if the alternative measure had the effect of consumers switching out of tuna, it would not make an equivalent contribution to the objective of informed consumer choice, while, if the alternative measure had the effect of some consumers switching from tuna not caught with purse seine methods to tuna caught with those methods, it would not make an equivalent contribution to the US dolphin protection objective. 
Finally, the AB considered Mexico's appeal of the Panel's finding concerning 'legitimate objective'. Mexico argued that the 'United States' dolphin protection objective is a "coercive objective" because its purpose is to "coerce" another WTO Member to change its practices to comply with a unilateral policy of the United States' (para. 335). The AB held that, to the extent that the US was concerned with 'coercing' Mexico to change its policies, this was not an 'objective' but a 'means' to obtaining the US dolphin protection objective. Mexico also argued that the US measure could not satisfy the requirements of 2.2 because it was inherently incapable of fully achieving the US objectives (this goes back to Mexico's observations about the imperfect or incomplete approach to dolphin-mortality observable in the US treatment of non-ETP tuna). The AB held that a measure need only make some contribution or fulfil the objectives to some extent. This makes obvious sense. A Member's right to regulate, and in particular its ability to pursue other legitimate objectives that might require some limit to the degree to which it fulfils the objective in question, would be seriously undermined if it had to pursue the objective to a fanatical degree and without regard to costs and trade-offs (Howse and Langille, 2012).

\section{5 'International Standards' (TBT 2.4)}

One of the key disciplines of the TBT Agreement is the obligation for WTO members to use relevant 'international standards' as a 'basis' for their technical regulations, unless the international standards are ineffective or inappropriate (Article 2.4). Yet international standards themselves are mostly of a voluntary nature and do not result, in most cases, in binding treaty commitments; quite a few of these standards are the creation of non-governmental bodies, or private/public partnerships where industry is the driving force. By virtue of Article 2.4 of the TBT Agreement, a very broad range of normative material, including privately generated norms in some cases, is converted or transformed into an international legal obligation.

In dicta in the EC-Sardines ${ }^{12}$ ruling, the Appellate Body has suggested that a 'very strong and substantial' relationship may be required between domestic regulations and international standards to satisfy the obligation under TBT 2.4 to use international standards as a 'basis'; the Appellate Body has clearly implied that international standards have considerable, automatic legal force in the WTO. The TBT Agreement nowhere defines international standards, nor does the Agreement attempt to list the international regimes that qualify to promulgate international standards within the meaning of TBT 2.4.

In its consideration of Mexico's claims under TBT 2.4, the Panel found that the AIDCP was an international standardization body, based in part on the

12 Appellate Body Report, European Communities - Trade Description of Sardines, WT/DS231/AB/R, adopted 23 October 2002, DSR 2002:VIII, 3359. 
determination that the AIDCP was 'open' to all WTO Members. The Panel made the legal interpretation that openness to all WTO Members includes a situation where the existing members of a body may, at their discretion, decide to accept a WTO Member as a new member of that body. ${ }^{13}$ The Panel also suggested that the criterion of 'openness' could be fulfilled if, during a certain temporal window, all WTO Members had an opportunity to choose to join the body. ${ }^{14}$ Not very surprisingly, the Appellate Body reversed the finding of the Panel that the AIDCP was a standardization body 'open' to all WTO Members. The AB acknowledged that at their discretion the states parties to the AIDCP could 'invite' a WTO Member to join the AIDCP, but was not persuaded that such an invitation was a mere formality, such that it would automatically follow from a WTO Member's expression of interest in becoming a Member. Thus the AIDCP is not 'open' to all WTO Members as a matter of right (paras. 397-399). There is an additional difficulty with the Panel's ruling which, however, the AB failed to address, but which is of considerable importance in understanding the scope of international standards within the meaning of TBT 2.4. The relevant language in TBT defining an international standardization body in TBT, as noted, refers to openness to Membership not by all WTO Members but the standardization bodies of all WTO Members. These bodies may be private industry or consumer bodies, mixed public/ private entities, or state agencies or entities. The AIDCP is a regional treaty regime, and as such arguably only a state or another entity with international legal personality (such as an intergovernmental organization) could be a 'member'-if indeed, 'member' means a party to the constitutive instrument of the regime. Given that standardization bodies will often lack the international legal personality to join international organizations or treaty regimes, there is a risk that the extremely important standardization activities of international intergovernmental organizations (ranging from the WHO to the IAEA to the ILO) would not qualify as international standards within the meaning of TBT 2.4. One solution would be to say that it is sufficient that every WTO Member be able to join the organization such that its standardization bodies, whether private, public or mixed, can participate in the standardization work in question through the Member's official delegation. Here, however, there is the concern that a state might have different positions in an international intergovernmental organization than those of a nonstate standardization body, and in any case would not want the activities or

13 Ibid. at para. 7.691 ('[T] he AIDCP remains open to accession to any State ... that is invited to accede to the Agreement on the basis of the parties' decision. To this day, the AIDCP membership is therefore open on a non-discriminatory basis to the relevant bodies of at least all WTO Members in accordance with the principle of openness.')

14 Ibid. (concluding that because the AIDCP membership was open from May 1998 until May 1999 to states whose vessels fished in the Agreement Area without restrictions on who could fish in the area, the AIDCP was open to all WTO Members). 
positions of the non-state body attributed to it. So this solution is not perfect. It also will not work where the international intergovernmental organization permits only states to be members, since not all Members of the WTO are states (e.g. Hong Kong). ${ }^{15}$

While reversing the Panel on whether the AIDCP is 'open' to all WTO Members, and failing to take account of the complexities just discussed, the $\mathrm{AB}$ did, to its credit, elaborate a broader framework for understanding the meaning of 'international standards' in TBT 2.4, offering useful guidance to future Panels.

First of all, the AB held:

a required element of the definition of an 'international' standard for the purposes of the TBT Agreement is the approval of the standard by an international standardizing body', that is, a body that has recognized activities in standardization and whose membership is open to the relevant bodies of at least all Members. As we see it, the different components of this definition inform each other. The interpretation of the term 'international standardizing body' is therefore a holistic exercise in which the components of the definition are to be considered together. (Para. 359)

Second, the AB noted:

'standardizing body', that is, a body with 'recognized activities in standardization', does not need to have standardization as its principal function, or even as one of its principal functions. At the same time, we note that the factual dimension of the concept of 'recognition' would appear to require, at a minimum, that WTO Members are aware, or have reason to expect, that the international body in question is engaged in standardization activities. (Para. 362)

This is an important finding, because, subject to the difficulty discussed above concerning openness to standardization bodies of all WTO Members, it allows the standardization activities of international organizations the main mandate of which is not standardization to nevertheless be eligible as international standards within the meaning of TBT 2.4. The same would be true of NGOs concerned with fair trade or sustainability, for example.

Third, the AB found:

the TBT Agreement also aims to encourage the development of international standards by bodies that were not already engaged in activities at the time of the adoption of the TBT Agreement. (Para. 379)

This is very important as international standards (codes of conduct) figure significantly in emerging issues such as sustainability of bio fuels and deforestation - for 
example, the relevant bodies may well not have existed prior to the creation of the WTO, especially NGOs.

Fourth:

The TBT Committee Decision assists in the determination of whether an international body has 'recognized activities in standardization'. As an initial matter, we note that the TBT Committee Decision establishes principles and procedures that WTO Members have decided 'should be observed' in the development of international standards. Evidence that an international body has followed the principles and procedures of the TBT Committee Decision in developing a standard would therefore be relevant for a determination of whether the body's activities in standardization are 'recognized' by WTO Members. More specifically, we recall that the word 'recognize' is defined as '[a]cknowledge the existence, legality, or validity of, [especially] by formal approval or sanction; accord notice or attention to; treat as worthy of consideration' and that the concept of 'recognition' has a factual and a normative dimension... other elements of the TBT Agreement, as well as the TBT Committee Decision, reflect the intent of WTO Members to ensure that the development of international standards take place transparently and with wide participation. The obligations and privileges associated with international standards pursuant to Articles 2.4 and 2.5 of the TBT Agreement further underscore the imperative that international standardizing bodies ensure representative participation and transparency in the development of international standards. In analyzing whether an entity is an 'international standardizing body', a panel needs to balance these considerations. (Paras. 376, 379)

The TBT Decision contains six principles, as Wijkstrom and McDaniels (2013) explain, of which the $\mathrm{AB}$ appears to give particular normative weight to participation and transparency. The six are: transparency (including that all proposals and final results be 'easily' accessible to all interested parties in all WTO Members); openness (including what would seem both de facto and de jure non-discriminatory participatory opportunities at all stages of standards development-impartiality and consensus); effectiveness and relevance (including prioritization of performance-based standards and a requirement not to give preference to the needs or interests of particular counties and regions); coherence (including cooperation and coordination with other relevant international standardization bodies); facilitation of meaningful participation of developing countries.

The AB finding that the Decision is relevant to the determination of whether a standardization body not merely is 'open' to all WTO Members but is engaged in 'recognized' standardization activities - an absolute legal precondition to the standard being an international standard within the meaning of 2.4 -implies that, since there is no list of 'recognized' bodies or activities within the TBT Agreement itself, each time there is a claim concerning an 'international standard' under TBT 2.4 the adjudicator must examine the extent to which the body emitting that standard meets in its activities the requirements of the six principles (not just those 
directly related to the meaning of 'openness'). ${ }^{16}$ This is a profoundly qualitative exercise, obviously, that entails an evaluation of aspects that go well beyond the particular standard being invoked in the dispute. This represents a major innovation in what Kingsbury and Stewart refer to as Global Administrative Law. In effect the $\mathrm{AB}$ has transformed what would be at best the 'soft law' of the Decision into a code of administrative procedure and practice for international standardization.

An extremely interesting question here is that of the dynamic effects on international standardization? Will international standardization bodies seek to examine and possibly reform their operations in order that their standards qualify under TBT 2.4? If so, the $\mathrm{AB}$ finding could well have the result of a considerable improvement in international standardization from the perspective of the values of Global Administrative Law. On the other hand, it is possible that some WTO Members might want to avoid the standards of a particular standardization body being invoked under TBT 2.4. In that instance, they might seek to ensure that the body in question does not operate in the manner required by the principles in the Decision.

More generally, given the significance now attached to the Decision by the AB, there is a need for more scholarly analysis of policy and of the exact provisions of the Decision and whether particular standardization bodies can be understood to conform to them. For example, what does it mean (under effectiveness and relevance) that standards should not 'distort the global market'? Standards may be aimed at addressing externalities, solving information failures, or dealing with coordination problems. The notion of not distorting global markets appears ideological, as if standards were not aimed at correcting already distorted global markets.

Finally, the $\mathrm{AB}$ use of the TBT Committee Decision gave it an opportunity to clarify the role of such normative material within the framework for treaty interpretation established under Articles 31 and 32 of the Vienna Convention on the Law of Treaties. The AB took the view that the Decision was a 'subsequent agreement' among the parties within the meaning of VCLT 31 (3)(a). This means that the adjudicator must take it into account where relevant, along with the 'context', as defined in VCLT 31(2).

\section{Economic analysis of Tuna-Dolphin II}

The Tuna-Dolphin II case raises a number of questions related to the economics of the TBT. From the perspective of economic analysis, this case is simply about

16 Wijkstrom and McDaniels (para. 3.24) appear to downplay the far-reaching significance of the $\mathrm{AB}$ finding concerning the Decision, seemingly ignoring or abstracting from the fact that in every case it will be necessary to establish that the body is 'recognized' in the relevant sense. 
information asymmetries among parties in the market and the use of informative labels as a Technical Barrier to Trade.

\subsection{What are the fundamental economic features of this case?}

Consumers in the United States purchase tuna produced in both the United States and Mexico. Although consumers cannot distinguish any observable difference between tuna caught in different locations or by different methods, some American consumers place a higher moral value on tuna caught using a specific technique that does not harm dolphins. Moreover, this dolphin-loving group of Americans is willing to pay a higher price in the market for a product that meets its higher ethical standards. While dolphin-loving consumers are highly concerned with animal welfare, it should be noted that dolphins are not endangered and thus do not fall under universally accepted standards for special protection.

In response to this concern for dolphin welfare among tuna-eating consumers, the US government created a voluntary labelling program in which tuna fishermen could have their catches certified as 'dolphin-safe'. This certification is costly to fisherman, but allows their product to be marketed in the US with an informative label that makes their product appealing to dolphin-lovers. Mexico made two important complaints about the US program. First, they claimed that the US labelling program was altering conditions of market competition to the detriment of Mexican producers of tuna. Second, they argued that an alternative labelling program, which they favoured and which essentially set a lower standard for dolphin care, should be allowed to co-exist in the US market.

The important legal questions raised in this case have already been analyzed in Section 2. In this section, we provide an economic analysis. As noted in Section 2.3, the Panel's finding concerning the universe of like products was not appealed by the US. Thus, from a legal perspective, the $\mathrm{AB}$ can be excused for not doing its own analysis of likeness. However, the way in which the Panel defined the universe of like products is questionable given the underlying facts. As will be discussed below, from an economic efficiency perspective, in order to correctly analyze the conditions of market competition, it is necessary to begin with an accurate definition of the relevant markets. Thus, our discussion of three key problems for economic analysis will at times go beyond the narrow scope of the problem directly before the $\mathrm{AB}$ to examine the case normatively.

1. What constitutes 'modifying conditions of market competition'? Further, how should Panels and the $\mathrm{AB}$ assess the extent to which conditions of market competition have been modified?

2. What are the welfare costs of a technical barrier to trade and who bears these costs?

3. When consumers value information regarding an internationally trade product, who should provide this information and who should choose the agent for provision of information? 


\subsection{Does the TBT modify conditions of market competition?}

Beginning with the first question, the Appellate Body reviewed the question of whether the opt-in labelling program run by the US modified the conditions of competition to the detriment of Mexican tuna products. The Appellate Body concluded 'it is the measure at issue that modifies the competitive conditions in the US market to the detriment of Mexican tuna products' (para. 240).

The AB's analysis begins with a clear statement of the relevant question for the $\mathrm{AB}$ to consider, 'whether governmental action "affects the conditions under which like goods, domestic and imported, compete in the market within a Member's territory"' (para. 236). The AB then drew a comparison to a case, Korea-Beef, in which the government's intervention into the market was fundamentally different from that in Tuna-Dolphin II. In the Korea-Beef case, the government imposed restrictions on retail outlets for beef. Essentially, by indirectly restricting access of foreign products to the domestic distribution network, the government directly inhibited competition between foreign and domestic beef. There is almost no similarity to the current case and it is hard to understand why the $\mathrm{AB}$ drew this parallel. In Tuna-Dolphin II, the government intervention is simply to create an informative label that designates whether a product, produced domestically or abroad, meets a specific 'high quality' standard.

A better approach to addressing the issue of market competition is to begin by determining whether the varieties of tuna products available for sale in the US are all part of one large indistinguishable 'tuna market' or whether there are distinct markets for different types of tuna. The fundamental features of the case suggest that there are at least two, and perhaps three, specific types of tuna that meet the preferences of US consumers to different degrees. The first type, which meets the US labelling requirements, could be called 'high ethical quality'; the second type, which meets the AIDCP labelling requirements favoured by Mexico, could be called 'moderate ethical quality'; and the third type could be called 'no ethical quality'. All three types presumably satisfy all physical standards of food safety. The economic problem in the tuna market is that different types of consumers prefer different types of tuna. Thus, in the absence of any labelling regime, all types of tuna are pooled into one unified market in which consumers who prefer 'high ethical quality' or 'moderate ethical quality' cannot have their preferences satisfied. In this case, the utility value that consumers ascribe to the different goods depends upon the value they place on the production process used, rather than any physical attribute of the good that eventually would be observable. Because consumers generally cannot observe the actual production process, but obtain utility from their beliefs about this unobservable feature, goods of this nature are known as credence goods.

In the absence of any correction of the information problem, one would expect that the US tuna market would exhibit a form of the classical 'lemons problem' (Akerlof, 1970). Because higher ethical quality (and consequently, higher cost) 
products could not be identified, the market would be dominated by items of no ethical quality and consumers who prefer higher ethical quality items would simply stop purchasing any tuna.

The standard solution to this type of market failure is to create either a public or private costly system of quality verification (Roe and Hicks, 2007). It is necessary that quality verification be costly because if there is no cost associated with proving quality, the low quality producers will attempt to mimic high quality producers with the result that the labelling system would have no value.

In light of this brief analysis of the information problem extant in the US tuna market, the AB's conclusion is questionable. Economic models of credence goods typically assume goods that are differentiated on unobservable processes embody different values (Roe and Hicks, 2007; Grolleau and Caswell, 2006). The prices paid for them, or their market worth, differ from the inherent value to the consumer unless the information problem is corrected. Under this framework, US governmental action to create labels is not modifying the conditions of market competition between like goods. Rather, the governmental action is correcting a market failure associated with the pooling of dissimilar goods into a single market. Therefore, the opt-in labelling program is strengthening the functioning of markets for all varieties of tuna.

This analysis presumes that there are, in fact, multiple markets for tuna products based on consumers' perceptions of the ethical quality of the production process. But, as an empirical question, how can and should a Panel or Appellate Body identify the boundaries of a 'market?' What evidence would support a conclusion that there are multiple differentiated tuna markets? Should the analysis focus on the demand side of the market, the supply side, or both? Ultimately, this will depend on the particular features of a case. ${ }^{17}$

In Tuna-Dolphin II, which centres around a government's desire to address consumer well-being, it seems natural to begin with the demand side of the market. The first question - does each variety of tuna constitute its own market - can be addressed by estimating consumer demand for each variety. While detailed data on prices and quantities of 'dolphin-safe', 'AIDCP-dolphin-safe' and 'not dolphin-safe' tuna are not available to the general public, grocery store chains in the United States regularly collect these data. ${ }^{18}$

Economists routinely estimate a parameter of consumers' demand functions known as the elasticity of substitution. This parameter captures how the quantity demanded of a specific product will respond to an increase in the price. More precisely, it reports the decline in the quantity demanded, expressed as a percent,

17 The Korea-Beef case cited above, which involved measures related to distribution of the products in question, seems to call for an analysis that focuses on the supply side of the market.

18 See Teisl et al. (2002), who use Panel data from A.C. Nielson to estimate tuna demand before and after the advent of dolphin-safe labelling in the United States. 
in response to a $1 \%$ increase in the price. A product with an elasticity of 5 will experience a $5 \%$ decline in the quantity demanded by consumers if its price rises by $1 \%$. Generally speaking, a product with a low elasticity ${ }^{19}$ is more highly valued by consumers in the sense that a moderately high increase in the price will result in only a small change in the quantity consumed. Items with lower substitution elasticities would include medications, higher quality goods, and more finely differentiated goods.

Consider what can be learned about markets for different tuna products by examining elasticities of import demand in the US. Soderbery (2013) provides estimates of import demand for different varieties of tuna in the US using publically available data at the HS10 tariff-line level. He finds that canned tuna excluding albacore (HS10 code 1604141010) has a very high elasticity of 47.14 while a related product, canned albacore tuna (HS10 code 1604141091), has a lower, yet still quite high, elasticity of substitution of 9.32. In the markets for these two products, producers must compete intensely because even a small increase in the price will lead consumers to dramatically reduce the quantity they will buy. See Figure 1 in which a small increase in the price from the equilibrium value of $P^{*}$ to $P^{\prime}$ is associated with a large decline in quantity consumed from $Q^{*}$ to $Q^{\prime}$. This is a common feature of commodity markets with little differentiation across goods. Markups, the increase in the price over the producers' marginal production costs, are often razor thin.

By way of contrast, consumer demand for frozen tuna is relatively inelastic. Frozen albacore tuna (HS10 code 0303410000) and frozen yellowfin tuna (HS10 code 0303420060) have estimated elasticities of only 2.74 and 1.42, respectively. For these products, price changes induce little change in the quantity demanded by consumers (see Figure 2). A substantial increase in the price from $P^{*}$ to $P^{\prime}$ is associated with only a small decline in the quantity demanded from $Q^{*}$ to $Q^{\prime}$. Producers thus have pricing power; the degree of competition is lower and producers can charge a comfortable markup over marginal cost.

These import demand elasticities for different varieties of tuna at the tariff-line level provide evidence that there are a number of distinct markets for tuna, and that the conditions of market competition vary considerably across these different goods. Further, for canned tuna, the extremely high elasticities of consumer demand provide evidence that competition is so intense that even very small increases in production costs would likely force some producers to exit the market.

Unfortunately, the most disaggregated products described in the US Harmonized system tariff schedule do not differentiate tuna according to the 'ethical quality' of the production process used. Thus, an analysis based on import demand elasticities at the tariff-line level cannot draw conclusions regarding whether or not

19 Note that any product with a 'low elasticity of demand' can also be described as 'inelastically demanded'. Conversely, 'high elasticity of demand' products have 'elastic demand'. 
Figure 1. Market equilibrium with elastic demand

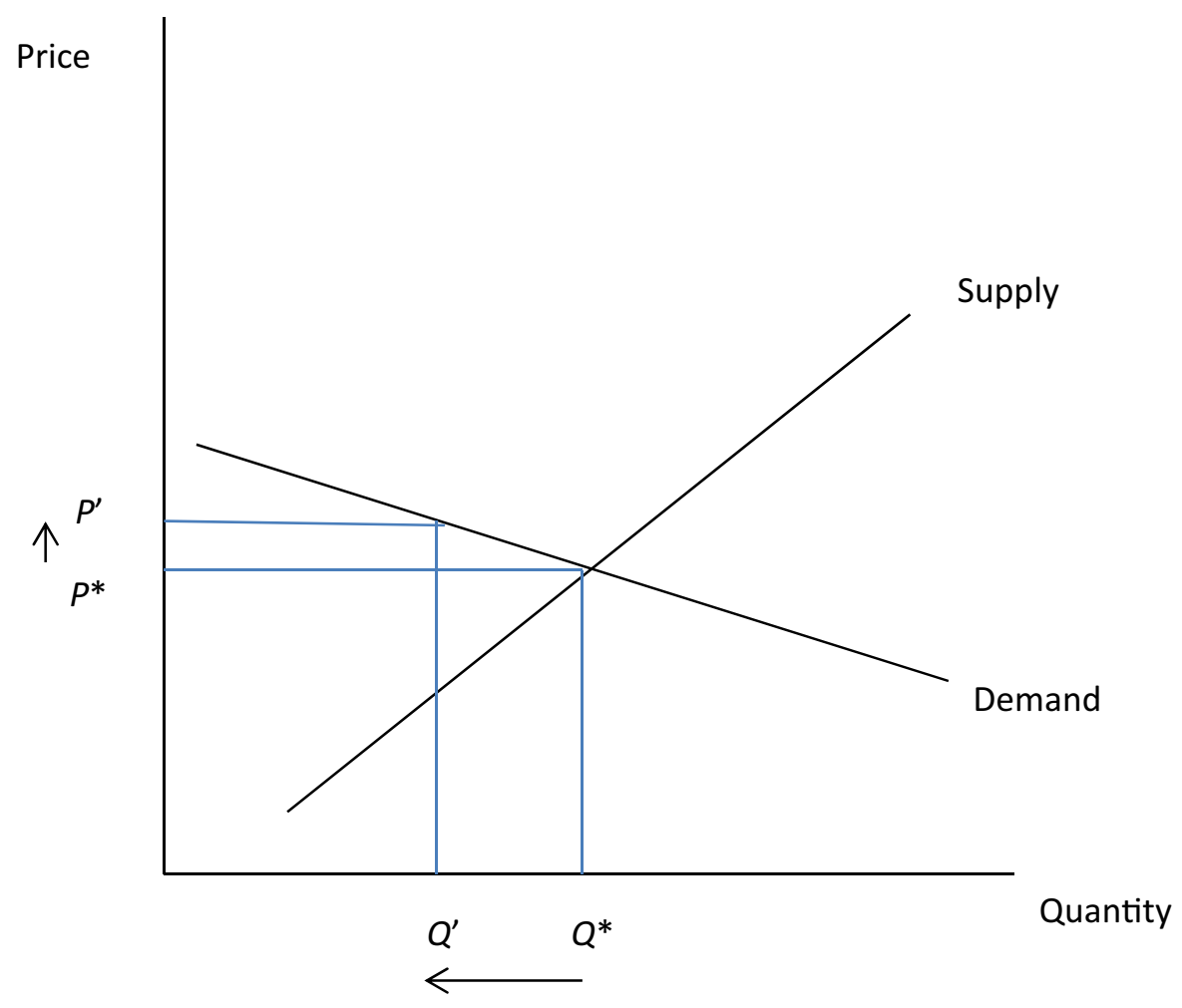

'US dolphin-safe' tuna, 'AIDCP safe' tuna, or 'no ethical quality' tuna are regarded as different goods by consumers. However, the same methodology used by Soderbery (2013) could have been used by the AB or by either party to the case to determine whether there is one unified market for tuna of different ethical qualities or several distinct markets.

In the AB's analysis of whether the 'dolphin-safe' labelling program modifies conditions of market competition (paras. 233-240), they abstract away from any analysis of what constitutes the market. Rather than beginning with an assessment of the boundaries of the different markets for tuna, they inherently assume the existence of a single unified tuna market. They then concur with the Panel that it is the label, not the inherent quality of the different products embodied in consumer preferences, that confers an 'advantage in the US market'.

This conclusion of the $\mathrm{AB}$ is consistent with a view that a dolphin-safe label provides a valuable service -i.e., independent third party verification of the dolphin-safe process - which is bundled together with the high ethical quality variety. Thus, a can of dolphin-friendly tuna with a label backed by third party 
Figure 2. Market equilibrium with inelastic demand

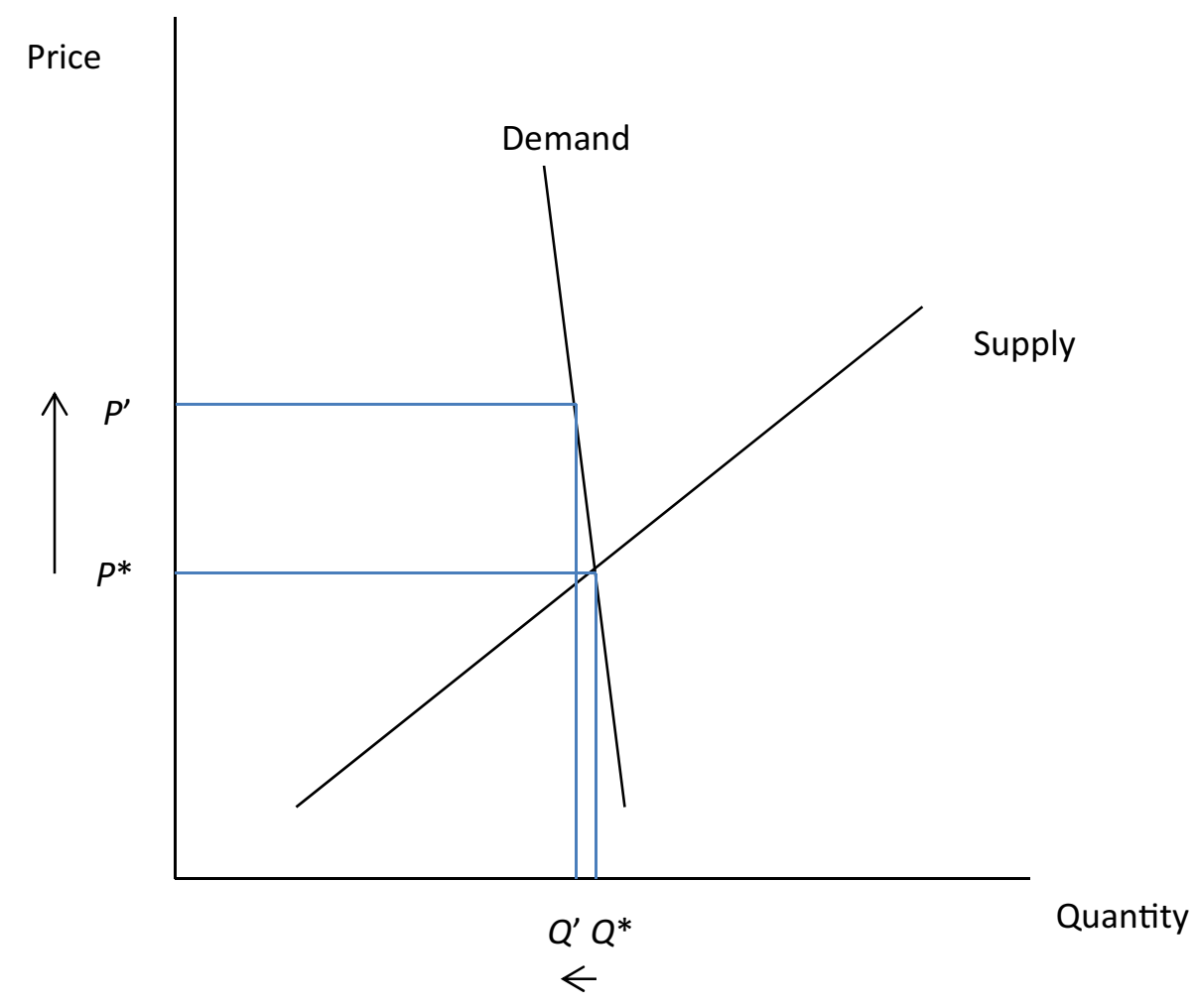

verification is worth more to consumers than a can with the same inherent qualities, but without the independent verification of those qualities. This line of reasoning leads to the further conclusion that it is the "lack of access ${ }^{20}$ to the "dolphin-safe" label of tuna products containing tuna caught by setting on dolphins has a detrimental impact on the competitive opportunities of Mexican tuna products in the US market'.

However, as noted above, the standard economic framework for analyzing information problems of credence goods treats a quality-validating label as a mechanism that facilitates the correct valuation of the good, rather than as a valuable product attribute in its own right.

This suggests that the $\mathrm{AB}$ finding is flawed by its failure to assess the underlying competitive conditions of the market. As the import demand elasticities provided by Soderbery suggest, higher quality types of tuna have lower demand elasticities 
and, consequently, higher markups and higher prices. The lower quality varieties of tuna face highly elastic consumer demand in the US.

If the $\mathrm{AB}$ had conducted an economic analysis of the tuna markets in the US, it seems very likely that they would have found that Mexican producers of moderate ethical quality AIDCP-labelled tuna and unlabelled tuna face very high demand elasticities in the US market. If so, then these higher demand elasticities would imply lower markups, lower prices, and lower profitability. Under this view, the only logical conclusion would be that the detrimental impact on Mexican producers of the US program arises because the Mexicans sell a different, and inferior, good.

As a final point, the AB finding (para. 407(b)) that the US program is inconsistent with Article 2.1 relies upon an assumption that 'dolphin-safe' and unlabelled tuna are like products. Given that the empirical evidence from consumer demand likely rejects this assumption, the $\mathrm{AB}$ finding is based upon a false premise. While the US did not claim that 'dolphin-safe' and other products served distinct markets, it is still problematic from an efficiency perspective that the conclusions were likely based on an incorrect assumption.

\subsection{The welfare costs of a TBT}

Turning next to our second question, we consider the welfare costs of a technical barrier to trade. The legal analysis of the case considered whether the US's 'dolphin-safe' program was a 'technical regulation' or a 'standard' under the TBT Agreement, whether compliance was mandatory, whether the program 'regulates in a binding fashion', etc. (paras. 11-18). The legal analysis also included extensive discussion of the 'legitimate objective' of the regulation.

In contrast, an economic analysis of the program simply focuses on the impact of the regulation (under any name) on consumer and producer welfare. ${ }^{21}$

As a first point of departure from the AB's legal analysis, we begin by observing that while promoting dolphin-welfare was one objective of the US program, another important objective of the program was to provide information to consumers that they found valuable. If we take information provision to consumers as the primary objective of US policy, then what does this imply about the welfare consequences of the program's design? Is the best program a mandatory one? A voluntary one?

If we wish to assess informative labelling regimes, the first question to consider is 'who should bear the cost of a labelling system?'

To simplify the analysis, suppose for the moment that there are two varieties of a product available in market, a 'high ethical quality' good and a 'low ethical quality' good and that the higher quality good faces a relatively inelastic consumer demand whereas the low quality good faces relatively elastic demand.

21 This section builds upon ideas laid out in Howse (2013a). 
Figure 3. The welfare burden of a voluntary labelling program

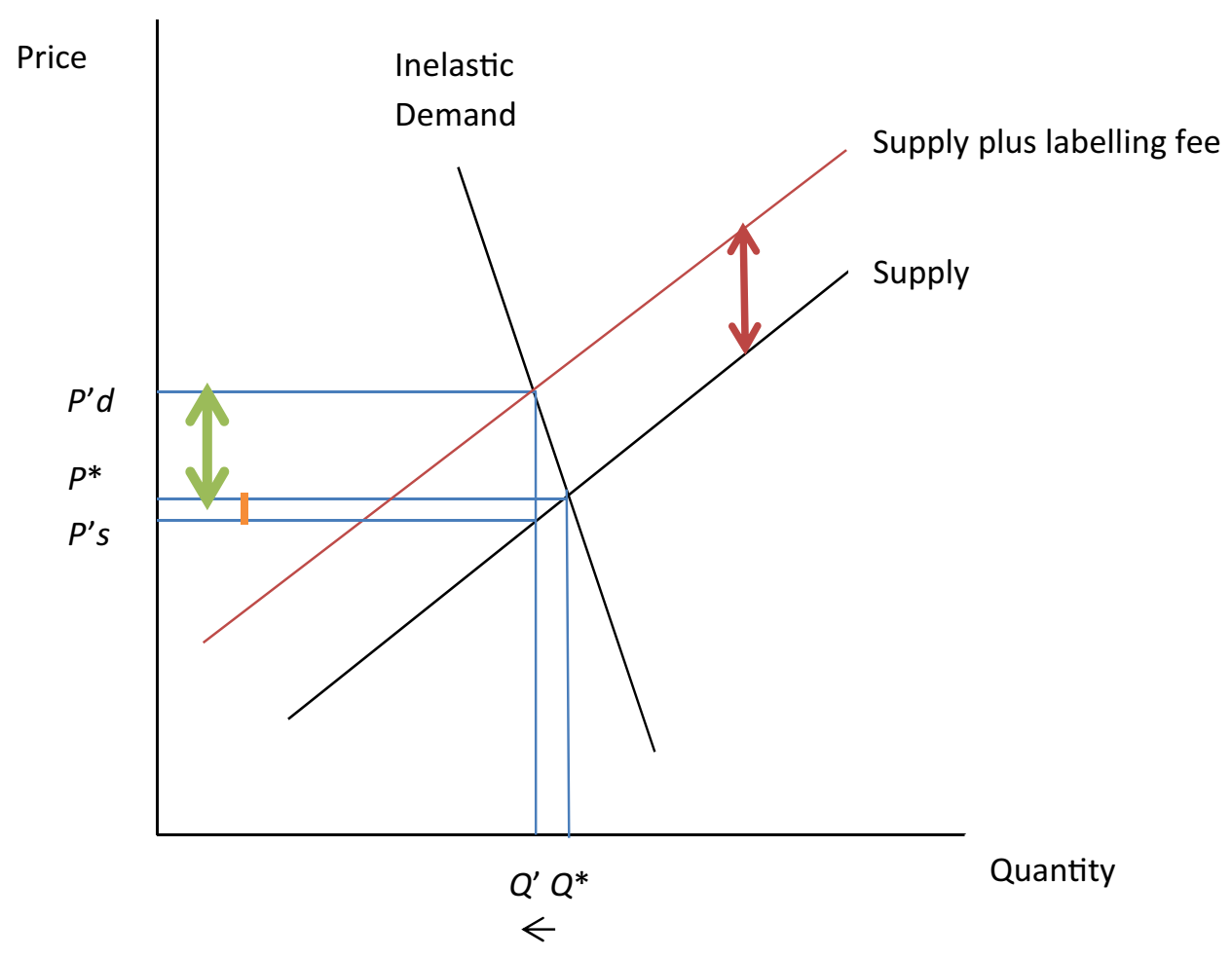

A voluntary labelling regime whereby it is costly to acquire a 'high ethical quality' label would involve some fee be paid (directly or indirectly) by producers of the high quality variety who desire the label for their product. Nothing would be required of low quality producers. Alternatively, a mandatory system would require both high and low quality producers pay a fee or incur a cost.

In order to evaluate the efficiency and fairness of both the voluntary and the mandatory regimes, we must first understand who bears the cost burden of the regulation, not in an accounting sense, but in a welfare sense. To do this, we can rely on the methods used in evaluating the burdens of tax policy. Thus, the elasticities of demand and supply for both the high ethical quality good and low ethical quality good will determine who bears the welfare cost of the regulation.

Consider first a voluntary labelling regime in which producers can choose whether or not to obtain a label that certifies their product as 'high ethical quality' for a fee. If consumer group one, the 'dolphin-lovers', prefers high ethical quality tuna and has a relatively inelastic demand for high quality, then they will bear most of the cost of the labelling regime (see Figure 3). Any fee required of producers, represented by the vertical height of the double-headed red arrow, will be largely 
Figure 4. The welfare burden of a mandatory labelling program

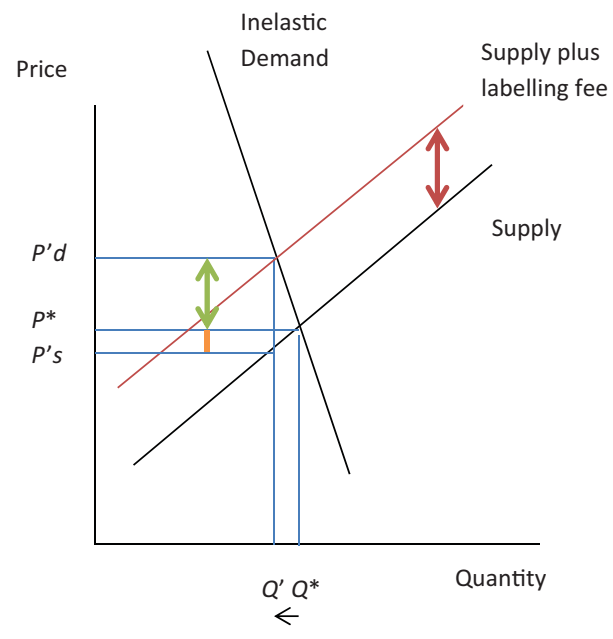

Panel A: The inelastically demanded variety

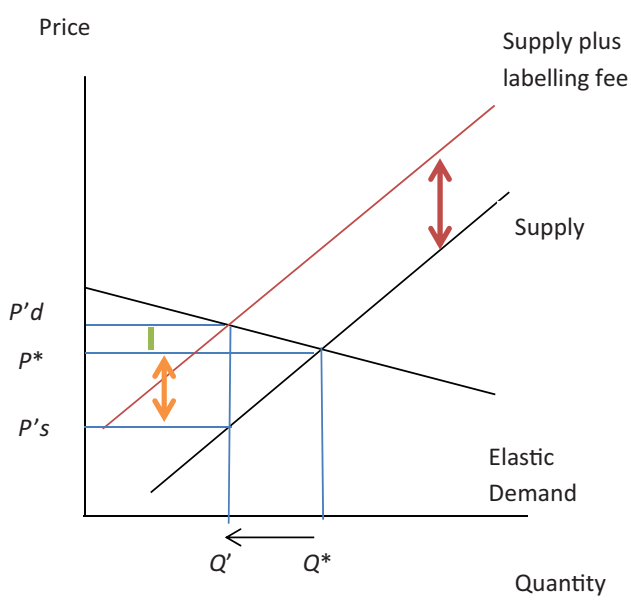

Panel B: The elastically demanded variety

passed through to consumers as a higher price they will pay, $P^{\prime} d$. Producers will receive a lower price, $P^{\prime} s$. However, the fraction of the total fee born by consumers, which is the ratio of the height of the green arrow to the height of the red arrow, is substantially larger than the fraction of the fee born by producers, the ratio of the height of the orange line to the height of the red arrow. With regard to fairness, this seems to be a reasonably good outcome because the group that values the information provided by the label is the group that pays the cost of the information. Of course, there will still be some 'marginal' consumers and producers who would like to buy and sell the high quality good, but will be forced to exit the market under this costly labelling system. These exiting agents are represented by the horizontal distance $Q^{*}-Q^{\prime}$. But, given the assumption of inelastic demand, the dead weight loss under this program, represented by the triangle with coordinates $\left(Q^{*}, P^{*}\right),\left(Q^{\prime}, P^{\prime} s\right)$ and $\left(Q^{\prime}, P^{\prime} d\right)$, would be small.

Next consider a mandatory labelling regime in which all producers must pay a fee to sell in the market (see Figure 4). After producers pay the fee, represented by the vertical height of the red arrow in panels A and B, their goods will be certified as 'high ethical quality' or 'low ethical quality'. Further suppose that consumer group two, 'dolphin-indifferent consumers', places no value on tuna fishing methods, but has highly elastic demand for tuna. Then, a mandatory labelling system that raises production costs for all producers, those providing high quality in panel A and low quality in panel B, could potentially have large negative welfare consequences. In the low quality market, the cost of the regulation would be largely born by the producers of low quality, rather than consumers. In panel $\mathrm{B}$, the producers' cost share of the regulation is the ratio of the 
heights of the orange arrow and red arrow. The price that low quality producers receive, $P^{\prime} s$, is substantially reduced by the labelling fee. More importantly, the existence of the regulation and the cost it imposes would induce a large number of marginal consumers and producers to exit the market for low ethical quality tuna. This exit is represented by the horizontal distance, $Q^{*}-Q^{\prime}$ in panel $\mathrm{B}$. Moreover, the dead weight loss in the low quality market, represented by the triangle with coordinates $\left(Q^{*}, P^{*}\right),\left(Q^{\prime}, P^{\prime} s\right)$ and $\left(Q^{\prime}, P^{\prime} d\right)$, is substantial.

This suggests that a voluntary labelling regime that charges producers of the inelastically demanded variety (i.e., high ethical quality tuna) a cost for participation would be welfare-superior to a mandatory labelling regime that spreads the burden evenly across all producers. It further suggests that, if we compare a regime of voluntary labelling of high quality to a regime of mandatory labelling in which all producers must share the cost of the regulation, it is the voluntary regime that has the smallest adverse impact on the low quality producers who face an elastic demand curve. Under the mandatory regime, many low quality producers would exit and the ones that continue to operate would bear the larger cost share of the labelling regime.

Altogether, this suggests that the US's voluntary program of labelling likely had the smallest negative impact on low quality Mexican producers of any program that satisfied the objective of informing consumers about product quality. By creating a program that allowed Mexican producers to abstain from participation, the US introduced no unnecessary welfare costs into the market for 'low ethical quality' tuna.

Interestingly, the conclusion to be drawn from an economic analysis of the welfare costs is that the domestic body which has the right to regulate, the US government, actually chose to implement the regulation in such a way as to minimize the adverse welfare consequences to foreign producers. The welfare analysis amplifies the legal arguments made in Howse's Amicus Curiae Submission to the $\mathrm{AB}^{22}$ - not only is the right to regulate a foundational principle that informs the balance of rights and obligations in the WTO system, but the execution of the right by a national government can potentially lead to more globally efficient policies.

\subsection{Who should provide information that enhances consumer welfare?}

The discussion of welfare costs leads us to a series of related empirical questions about provision of information to consumers. First, what is the optimal quantity of information that should be provided to consumers? Second, what entity-a domestic national government, a foreign national government, an international 
standards body, a private association of producers or retailers, a private consumer watchdog, or the WTO-should provide the information? Finally, what entity should decide who provides the desired information?

In the Tuna-Dolphin II case, Mexico contended that 'both the AIDCP dolphinsafe standard and the US dolphin-safe standard could co-exist, each subject to its own labelling requirements' (para. 47). Setting aside the fact that the proposal for multiple labels came from Mexico, what are the economic merits of the Mexican proposal?

Suppose that the US tuna market consists of several products of differing quality, as described in Section 3.2. In this environment, the Mexican suggestion to allow for labels that indicate different levels of quality - high, medium, and low-could yield greater welfare than a regime of only two quality grades-high and low. The optimal number of quality gradations must be determined empirically and involves tradeoffs. On the one hand, if information is costless, economic efficiency would favour a large or infinite number of labels that provides to each consumer the precise information that enables the consumer to choose their most preferred variety. However, because information is costly to provide, the optimal number of quality gradations is finite, and likely quite low. ${ }^{23}$ Moreover, even if information is costless to provide, a wealth of recent work in economics has documented anomalies or irrational choices by consumers which suggest that consumers often fail to correctly process all available information regarding product attributes. ${ }^{24}$ If consumers face too much information, then this excess information can lead to confusion. Consequently, confused consumers could choose products that do not best satisfy their preferences.

To summarize, in comparing two different policy proposals - the Mexican proposal for co-existence of multiple labels versus the US's program of two quality grades - it is not clear which policy yields higher welfare. An empirical evaluation of the two policy options requires that the policy maker be informed about consumer preferences over different varieties (e.g., through demand elasticities) and about consumers' abilities to process any information provided by a labelling regime. The choice of a policy must balance the gains of greater information against the costs of greater information.

This leads to us to the two related questions mentioned previously-who should provide the information and who should decide who provides the information.

Economic analysis provides no uniform rule regarding which entities should provide information to consumers. There are examples of information provision

23 Roe and Hicks (2007) compare efficiency under both discrete and continuous labels.

24 Campbell et al. (2011) survey the literature on consumer choices over financial products. Fehr and Rangel (2011) describe the efforts to understand problems of complex consumer decision-making using neuroeconomics. 
from a wide variety of agents. When product quality directly affects human health, as in food or drug safety, the US government typically fills the role of quality regulator and information provider for US consumers. At the other extreme, during the recent scandal in China over life-threatening contamination of powdered baby milk, Chinese consumers lost faith in their domestic regulators and have sought to purchase foreign-produced baby milk because they have greater faith in the effectiveness of foreign regulators to safeguard human health. Between these extremes, we observe consumer-funded groups providing quality ratings for goods and services ranging from autos and electronics to hair stylists and plumbers while 'independent', private ratings agencies (that rely on income from producers) are responsible for assessing the quality of bonds and other financial instruments that trade in the US. Ultimately, the choice of an entity to provide information depends upon the nature of the product, the costliness of providing information and the incentive structure that induces the most truthful revelations about a product.

This leads to the question of who should choose the regulator.

The preamble to the Agreement on Technical Barriers to Trade clearly places the right to regulate under a national authority. Economic efficiency would support this placement on the grounds that consumer welfare is best served when a government chosen by consumers is responsible for establishing regulations.

This implies that the Panel's decision to give itself the right to choose the regulator by advancing the proposed Mexican labelling scheme over that of the US appears wrong from an economic as well as a legal viewpoint. Thus, the AB finding that the Panel erred by concluding that the US labelling program was more trade restrictive than necessary enhances economic efficiency to the extent that it returns the right to establish a regulation back to the national government which is best positioned to advance the objective of consumer welfare.

\section{Conclusion}

The economic analysis of Tuna-Dolphin II examined three questions: (1) how should a WTO body determine whether a technical barrier to trade (TBT) modifies conditions of market competition, (2) who bears the welfare costs of a TBT, and (3) who should provide valuable information to consumers. We suggest that an empirically accurate like-product determination is a necessary first step in analyzing market competition; in some cases, consumer demand elasticities will be highly informative to judicial authorities. Further, demand elasticities can aid judicial authorities in understanding the distributional consequences of regulations. Lastly, consumer information is provided by many different agents and institutions within an economy - the best agent or institution for providing information will tend to be the one facing the strongest incentives for truthful revelation. 


\section{References}

Akerlof, G. A. (1970). 'The Market for 'Lemons': Quality Uncertainty and the Market Mechanism', Quarterly Journal of Economics, 84(3): 488-500.

Campbell, J. Y., H. Edmunds, J. Brigitte, C. Madrian, and P. Tufano (2011), 'Consumer Financial Protection', Journal of Economic Perspectives, 25(1): 91-113.

Fehr, E. and A. Rangel (2011), 'Neuroeconomic Foundations of Economic Choices-Recent Advances', Journal of Economic Perspectives, 25(4): 3-30.

Howse, R. (2012), Before the World Trade Organization Appellate Body: United States-Measures Concerning the Importation, Marketing and Sale of Tuna and Tuna Products (AB-2012-2/DS381), Amicus Curiae Submission, 17 February 2012, paras. 8 and 9.

— (2013), 'Consumer Labeling on Trial at the WTO: Misunderstanding the Behavioral Law and Economics of Consumer Information, New York University mimeo.

Howse, R. L. and J. Langille (2012), 'Permitting Pluralism: The Seal Products Dispute and Why the WTO Should Permit Trade Restrictions Justified by Non-Instrumental Moral Values', Yale Journal of International Law, 37(2).

Howse, R. and P. I. Levy (2013), 'The TBT Panels: US-Cloves, US-Tuna, US-Cool', World Trade Review, 12(2): 327-375.

Grolleau, G. and J. A. Caswell (2006), 'Interaction Between Food Attributes in Markets: The Case of Environmental Labeling', Journal of Agricultural and Resource Economics, 31(3): 471-484.

Kingsbury, B., N. Krisch, and R. B. Stewart (2005), 'The Emergence of Global Administrative Law', Law and Contemporary Problems, 68: 15-62.

Roe, B. and I. S. Hicks (2007), 'Credence Good Labeling: The Efficiency and Distributional Implications of Several Policy Approaches', American Journal of Agricultural Economics, 89(4): 1020-1033.

Anson Soderbery (2013), 'Estimating Import Supply and Demand Elsasticities: Analysis and Implications', Working Paper, Department of Economics, Purdue University, West Lafayette, IN, 22 April 2013.

United Nations (1969), 'Vienna Convention on the Law of Treaties', 23 May 1969, United Nations, Treaty Series, vol. 1155, p. 331, available at: http:/www.refworld.org/docid/3ae6b3a10.html.

Teisl, M. F., B. Roe, and R. L. Hicks (2002), 'Can Eco-Labels Tune a Market? Evidence from Dolphin-Safe Labeling', Journal of Environmental Economics and Management, 43(3): 339-359.

Wijkstrom, E. and D. McDaniels (2013), 'International Standards and the WTO TBT Agreement: Improving Governance for Regulatory Alignment', World Trade Organization Economic Research and Statistics Division, Staff Working Paper ERSC-2013-06, 25 April 2013. 